\title{
Zuallererst kein Sport ...
}

... soll Winston Churchill angeblich auf die Frage nach dem Erfolgsrezept für sein hohes Alter geantwortet haben. Angeblich, da sich nirgendwo Belege dafür finden. Ist aber egal. Auch wenn er es niemals gesagt hat Recht hat er trotzdem. Denn Sport ist gefährlich! War er schon immer. Bereits vor 2500 Jahren wurde der griechische Bote Pheidippides auf dem Weg von Marathon nach Athen Opfer seines ungestümen Bewegungsdrangs [1]. Immerhin hatte er als Übermittler einer wichtigen Nachricht noch einen triftigen Grund, sein Leben mit Sport aufs Spiel zu setzen. Aber heute, nach der Erfindung der Schweizer Post ... da sollte doch der gemütliche Gang zum Briefkasten ausreichen. Sollte, ist es in alarmierender Weise aber nicht. Viele treiben aus Naivität oder Ignoranz Sport; der regelmässige Gang (oder Liegendtransport) zum Orthopäden und Physiotherapeuten ist so selbstverständlich wie Zähneputzen geworden.

\section{Ignorantia facti non excusat!}

Lieber Bruno, nicht dass Du uns später einmal vorwirfst: «Mich hat ja keiner gewarnt!» Gerüchten zufolge willst Du Dein Mehr an Freizeit u.a. mit einem Mehr an Tennis füllen. Äusserst bedenklich! Von sämtlichen Sportarten ist Tennis die gefährlichste - Statistiken, die das Gegenteil behaupten: alle «Fake News». Welche andere Sportart kann von sich behaupten, Namensgeber so vieler Fehlbelastungsund Verletzungsfolgen zu sein: Tennisschulter, Tennisellenbogen, Tennisbein, Tenniszeh, nur um einige zu nennen. Schon dem Namen des Sportgeräts Tennisschläger wohnen Rohheit und Gewaltbereitschaft inne. Deutet der Begriff Breakball nicht auf eine drohende Fraktur hin? Und Big Point darauf, wenn sie tatsächlich eintritt? Ich warne also!

Gibt es Alternativen zum aktiven Tennissport? Wie wäre es mit einer Spielkonsole und virtuellem Tennisspielen? Nein, auch hiervon ist abzuraten. Eine 55-jährige Frau erlitt dabei einen traumatischen Hämothorax, weil sie in der Hitze des Gefechts eine Bekanntschaft der anderen Art mit der Sofakante machte. Klingt nach Boulevardzeitung, ist es aber nicht. Der Fallbericht wurde in einer seriösen Fachzeitschrift veröffentlicht [2]. Und solltest Du denken, Ärzten passiert das nicht, verweise ich auf einen weiteren Fall im New England Journal of Medicine [3]: Nach stundenlangem Tennisspielen auf seiner Wii-Konsole hatte sich die Infraspinatussehne eines 29-jährigen Arztes unter heftigen Schmerzen akut entzündet. Die Diagnose «akute Wiiitis» erlebte ihre Geburtsstunde.

\section{Auch passiver Sport ist keine Lösung}

In den 1950er Jahren wurde das Fernsehen erfunden, um sich an sportlichen Höchstleistungen zu berauschen - ohne selber seine Gesundheit aufs Spiel setzen zu müssen. Ist Tennis im Fernsehen der Ausweg aus dem Dilemma? Doch dass Zuschauen bei sportlichen Ereignissen risikolos ist, wurde durch eine Studie im New England Journal of Medicine in

Frage gestellt [4]. In dieser ging es zwar um Fussball, nicht um Tennis, aber das spielt hier keine Rolle (die Unterschiede sind ja auch nicht so gross: Ball, Netz, kurze Hosen...). Gemäss einer Forschergruppe aus München erlitten an Tagen, an denen während der Fussball-WM 2006 die deutsche Mannschaft spielte, 3-mal so viel Männer wie üblich einen kardialen Notfall. Fazit: Sport schauen macht Stress. Und Stress kann tödlich sein. Bei Tennis mögen die Folgen vielleicht nicht ganz so dramatisch sein ..., aber dieser störende Nystagmus, ausgelöst durch die ständigen Ballwechsel ...

\section{Was ich noch zu sagen hätte ...}

Lieber Bruno, ich meine es nur gut! Lies ein anregendes Buch (oder die SÄZ)! Atme frische Luft! Ernähre Dich gesund! Aber lass die Finger vom Sport, insbesondere vom Tennis. Viel zu gefährlich!

Ich bedanke mich für eine fast 15 -jährige produktive, kreative und vertrauensvolle Zusammenarbeit. Sie wird mir in bester Erinnerung bleiben. Für die nächste Phase Deines Lebens wünsche ich Dir mit Kölsch und auf Kölsch «Maach et joot»!

Peter (Kleist)

Bildnachweis

Tennisschläger: @ Iconisa | Dreamstime.com; (nur Schläger und Ball) 